\title{
Avatares del profesional de la información al organizar y representar el conocimiento en la WEB
}

\author{
Yanai Valdés López \\ Saber Angola, Angola \\ Profesora adjunta de la Facultad de Comunicación de la \\ carrera de Bibliotecología y Ciencias de la Información. \\ Licenciada en bibliotecología y ciencias de la información \\ por la Universidad de la Habana. Especialista del grupo \\ de automatización de la dirección científico técnica de la \\ Universidad de la Habana. \\ E-mail: valdeslopez84@gmail.com
}

\section{Resumen}

Se analiza el cambio cultural que ha de sufrir el Profesional de la Información para implicarse en los procesos de Organización y Representación del Conocimiento. Se enuncian algunos métodos de investigación propicios para la Organización y Representación del Conocimiento. Son analizadas algunas tendencias para Organizar y Representar el Conocimiento en la Web: Blog, Taxonomías, Folksonomías, Ontologías, Web Semántica. Se reflexiona en torno a la integración interdisciplinar del Profesional de la Información y se exponen criterios a cerca de las actitudes y/o habilidades que necesita el Profesional de la Información para Organizar y Representar el Conocimiento en la WEB.

\section{Palabras Clave}

Organicación y Representación del Conocimiento; Profesional de la información; Cibercultura.

\section{Avatars of professional organizing information and knowledge representation on the WEB}

\begin{abstract}
s
We analyze the cultural change that has suffered the Information Professional to engage in processes of Organization and Knowledge Representation. They embody some research methods conducive to the Organization and Representation of Knowledge. Some trends are analyzed to organize and represent knowledge
\end{abstract}

on the web: Blog, taxonomies, folksonomies, ontologies, Semantic Web. It reflects on the interdisciplinary integration of the Information Professional and outlines criteria about the attitudes and / or skills needed by the Information Professional to organize and represent the knowledge on the web.

\section{Keywords}

Organization and representation of knowledge; Professional information; Cyberculture.

\section{INTRODUCCIÓN}

Durante años el pensamiento del profesional de la Información ha estado respaldado por principios, teorías y postulados concebidos con el surgimiento de la Bibliotecología como ciencia en el siglo XIX y su posterior desarrollo en el siglo XX. Siglo que marca una impronta tecnológica con el nacimiento de fenómenos comunicacionales, bautizado como "el siglo de las comunicaciones".

El fin de siglo, nos ubica en un mundo en reconstrucción, transitando hacia la denominada "sociedad de información", con él fenómeno revolucionario conocido como Internet ${ }^{2} \mathrm{y}$ demás tecnologías digitales relacionadas a ella. Proporcionando un notable desarrollo en todos los sectores de la sociedad debido al volumen de conocimientos que en esta red están dispuestos.

\footnotetext{
${ }^{1}$ Nace el telégrafo, el teléfono, la radio, la televisión el cine, los satélites.

${ }^{2}$ Internet es un conjunto descentralizado de redes de comunicación interconectadas. Sus orígenes se remontan a 1969, cuando se estableció la primera conexión de computadoras. Uno de los servicios que más éxito ha tenido en Internet ha sido la World Wide WEB (WWW, o "la WEB").
} 
El siglo XXI marca el nacimiento de una nueva sociedad la de la información. Sociedad que se organiza en redes y se ha extendido a facetas insospechadas de la vida social, aprovechando los espacios digitales o ciberespacios. Espacios, dotados de culturas particulares, reflejos de sus creadores y utilizadores. El conocimiento surgido de las relaciones comunicacionales que se dan en la red conforman hoy parte del patrimonio de la humanidad, en cuanto es un fenómeno emergente sin indicio alguno a desaparecer. Uno de los recursos vitales de esta sociedad contemporánea es la información; recurso intangible del cual para obtener su máximo beneficio es imprescindible su organización y tratamiento. A este fenómeno hace alusión (Choo, 1999) y plantea que "los sistemas para el procesamiento de información de nuestro mundo contemporáneo nadan en una sopa extraordinariamente rica de información. En un mundo de este tipo, el recurso escaso no es la información es la capacidad de procesamiento para atender la información'.

Con lo anterior como supuesto el Profesional de la Información (PI) ha de contextualizar dichos cambios, transformando su actitud e interrogándose acerca de vías para Organizar y Representar el Conocimiento. Vías que emergen a partir de la explosión de información y el conocimiento, derivado de la aplicación de las Nuevas Tecnologías de la Información y las Comunicaciones (NTIC). Ello suscita inevitablemente un cambio radical en su cultura ${ }^{3}$. La pretensión de este trabajo, estriba justamente en exponer algunas ideas en torno a las modificaciones culturales que frente al fenómeno de la WEB, el Profesional de la Información irreversiblemente deberá enfrentar.

\section{APROPIACIÓN AL FENÓMENO DE LA CIBERCULTURA POR PARTE DEL PROFESIONAL DE LA INFORMACIÓN}

Desde hace cientos de años el PI ha desarrollado su práctica sobre la base de una cultura informacional

\footnotetext{
${ }^{3}$ Todo ser humano vive en la esfera de su cultura, en un contexto coordinado de valores, creencias, conceptos y simbolizaciones que la constituyen. Rodríguez, F. (2003). Cultura y televisión. Una relación de conflicto. Editorial Gedisa, Barcelona. Pp.12
}

positivista al Organizar y Representar procesos que con las NTIC han incorporado cambios en su praxis, re- direccionando la milenaria cultura informacional de este profesional.

Al respecto Codina (2001) expone que el pensamiento ha estado anclado tradicionalmente en la práctica de los principios, las técnicas y herramientas de descripción de los contenidos documentales, extrayendo y modelando su esencia con el fin práctico de que los usuarios accedan a la información representada.

Tradiciones que han estado relacionadas con la descripción de la forma y el contenido en la etapa de procesamiento de la información, fase imprescindible para la Organización y Representación de la Información (ORI).

El procesamiento de la información ha sido una práctica que usualmente se ha desarrollado a través de la catalogación, la clasificación, la indización y el resumen. En el primer caso, obteniendo con el apoyo de formatos y normas, elementos que describan las características físicas del objeto. Los restantes son procesos en los cuales se analiza su contenido, en los que se obtienen los elementos más relevantes que identifiquen al objeto.

En la Organización y Representación de la información no sólo se destaca la etapa de procesamiento de la información; en ella también confluyen otras etapas como la selección, almacenamiento, búsqueda, recuperación y diseminación de la información (Vizcaya, 2000) que permiten visualizar de manera holística y sinérgica la actividad procesual dentro de la ORI.

Como se planteó anteriormente, el PI dirige sus pasos por nuevos rumbos. Se impone un contexto que demanda de nuevas y urgentes soluciones y alternativas. Describir y representar la información, deviene entonces en una actividad que va más allá de la mera descripción que contienen los documentos. Es preciso interpretar los cambios en las formas de producción, comprensión y utilización 
de los mismos en sus contextos. Tales razones conducen a cuestionar los métodos y maneras de hacer para describir el conocimiento contenido en los nacientes recursos de la $\mathrm{WEB}^{4}$, a través de la utilización de herramientas que permitan al PI, dilucidar la realidad con un enfoque socio cognitivo. Se trata entonces de trazar nuevas estrategias que conduzcan a la Organización y Representación del Conocimiento.

Su noción es entendida como "Organización del Conocimiento en un sentido estrecho, es sobre los Sistemas de Organización del Conocimiento y sobre los Procesos de Organización del Conocimiento, donde los sistemas son los lenguajes de representación mientras que los procesos son las tareas llevadas a cabo para representar el conocimiento a través de estos lenguajes”. (Hjorland, 2005)

En un sentido más amplio la Organización y Representación del Conocimiento está relacionada también con los tipos de conocimiento que en un contexto pueden convergir. El conocimiento entendido desde la perspectiva de (Nonaka y Takeuchi, 1997) tiene dos lecturas con respecto al conocimiento humano, pudiendo ser tácito o explicito.

Los estudios de estos autores aportan al PI formas para la producción de nuevo conocimiento, ayudando a gestionarlos con apoyo en innumerables herramientas tecnológicas que socializan el conocimiento en comunidades específicas de saber.

En opinión de la autora la organización del conocimiento pretende ofrecer un modelo conceptual adecuado con las diversas actividades sociales y las prácticas relacionadas con el acceso al conocimiento y la intención de funcionar como una herramienta para el tratamiento de la información y el uso de gestión de la información. Abarca además la integración de los fenómenos y las aplicaciones vinculados con la estructura, el

${ }^{4}$ Conjunto de protocolos que permite, de forma sencilla, la consulta remota de archivos de hipertexto. diseño, el acceso y la difusión del conocimiento socializado.

Es por hecho que la implicación del PI en la Organización del Conocimiento supone un cambio en su cultura, que guíe sus patrones culturales hacia la comprensión y aprehensión de los procesos culturales que tienen lugar hoy en la Sociedad de la Información y el Conocimiento. De esta forma podrá ampliar su cosmovisión de lo que se denomina hoy Cultura digital o Cibercultura entendida como "estadio de desarrollo social caracterizado por la capacidad de sus miembros (ciudadanos, empresas y administración pública) para obtener y compartir cualquier información, instantáneamente, desde cualquier lugary en la forma que se prefiera. (Castells, M. 1999)

Para (López, J.2004) la Cibercultura es entendida como un "conjunto de tradiciones comportamentales, conceptuales, literarias y artísticas que han surgido en torno al uso de internet, desde, por y para sus usuarios, los internautas. Del mismo modo que la cultura contemporánea, se trata de un mundo diversificado, fragmentado y en permanente interacción en el que conviven y desarrollan productos y pautas sociales grupos muy diversos que mantienen una interacción intensa [...] con la cultura de la globalización, de la que internet no es sino un medio privilegiado de enculturación y expresión."

Este fenómeno cultural ha de ser enfocado como una práctica, en el que están implicados procesos comunicativos cuyos actores como miembros de las comunidades virtuales producen y trasmiten significados, en un medio de constante interacción, en el que expresan y comunican sus costumbres, valores y maneras de percibir el mundo.

Para el PI el cambio cultural debe ser atendido desde ya no sólo desde el punto de vista práctico sino también desde teorías y supuestos que expliquen tales prácticas e incluso permitan mejorarlas. El PI ha de convertirse un ente activo y participante; capaz de adaptarse y entender las complejas dinámicas 
que establecen los medios con que interactúan, de manera que puedan descifrar los nuevos sistemas vigentes $^{5}$, que en la WEB que emerge construyen las Representaciones Sociales.

Estas "se presentan bajo formas variadas, más o menos complejas. Imágenes que condensan un conjunto de significados; sistemas de referencia que nos permiten interpretar lo que nos sucede, e incluso, dar un sentido a lo inesperado; categorías que sirven para clasificar las circunstancias, los fenómenos y a los individuos con quienes tenemos algo que ver; teorías que permiten establecer hechos sobre ellos. Y a menudo, cuando se les comprende dentro de la realidad concreta de nuestra vida social, las representaciones sociales son todo ello junto." (Jodelet, 1988).

Amén de que las reflexiones de este autor desde el campo de la Psicología daten de 1988 se avienen íntegramente a estos tiempos, desde una perspectiva Socio Psicológica; en tanto advierte formas en que han de ser comprendidas las maneras de pensar de tales representaciones de la sociedad a través de procesos comunicativos.

El PI tendrá entonces que estar capacitado para recrear, reproducir o recomponer aquellas realidades que emanan de las comunidades virtuales. Se hace necesario conocer de las mismas elementos de orden conductual, valores, hábitos, comportamientos, presunciones, modus operandi, entre otros, en virtud de dar las respuestas que exigen estas comunidades tan dinámicas como diversas.

\section{MÉTODOS DE INVESTIGACIÓN PROPICIOS PARA EL PI DESDE UNA PERSPECTIVA INTERDISCIPLINAR}

El tratamiento del conocimiento es un tema complejo que exige una aproximación de forma interdisciplinar ${ }^{6}$. Para las Ciencias de la Información

\footnotetext{
${ }^{5}$ Sistemas de Escritura, Sistemas de Lectura, etc.

${ }^{6}$ Proceso de establecimiento de vínculos entre disciplinas o campos de conocimiento en función de un problema compartido Es un nivel más complejo de integración, en el que se establecen interacciones entre dos ó más disciplinas, donde se definen objetivos comunes; alli se produce intercomunicación y enriquecimiento recíprocos y hasta transformaciones de orden metodológico
}

su estudio ha de verse de forma integrada desde el diálogo de disciplinas diversas. En ese sentido al abordar la Organización y Representación del Conocimiento se importan técnicas, modelos, teorías y metodologías de diferentes áreas del saber. Pues el campo se deriva de, o se relaciona con las ciencias matemáticas, las ciencias de la comunicación, las ciencias de la computación, la psicología y por tanto el PI ha de implicarse de forma interdisciplinar con ellas para recibir sus aportes teóricos y metodológicos.

Los aportes de cada una de las ciencias mencionadas permiten conocer teorías de la comunicación, aplicaciones informáticas, terminologías, análisis del discurso, formas de comportamiento, etc.

El PI entenderá mejor las representaciones sociales en la medida en que sea capaz de involucrarse más en estudios Etnográficos o que Analicen el Dominio, formas diferentes de estudios de los fenómenos provenientes de otras ciencias.

La primera constituye un tipo de investigación cualitativa $^{7}$ ampliamente utilizada en las Ciencias Sociales $^{8}$ que tiene como tendencia "la descripción cultural basada en la participación del investigador en la dinámica del grupo en un periodo de tiempo, describiendo su cultura como conocimiento compartido y entendido de sentido común de los miembros de un grupo determinado apropiado a tal escenario" (Muela, \& Zapopan, 2004).

El denominado Análisis de Dominio se interpreta como "disciplina cientifica o un campo académico; una comunidad del discurso conectada a un partido politico, una religión, un comercio, o una afición" (Hjorland, s.a). En otro de sus trabajos, el propio autor expone además, que la mejor vía para estudiar el conocimiento de los dominios es el Análisis del

\footnotetext{
${ }^{7}$ Explican los hechos de la vida social de los sujetos dentro de su entorno. Describe en detalle el contexto, los sentidos y los significados de los eventos relevantes de un objeto de estudio. Es fundamentalmente interpretativa. Es necesariamente subjetiva (sentido y significado). Notas de clase Maestría BCI. Metodología de la Investigación.

${ }^{8}$ Las ciencias sociales son aquellas ciencias o disciplinas científicas que se ocupan de aspectos del comportamiento y actividades de los humanos.
} 
Discurso ${ }^{9}$, analizando sus formas de comunicación y la subjetividad de sus criterios (Hjorland, s.a).

Es innegable la implicación del PI en este tipo de estudios para representar el conocimiento, basada en la mejor compresión de las problemáticas sociales del contexto que estudia. Mientras más involucrado e identificado esté el PI con el contexto mejor podrá representar la cultura del mismo en las plataformas donde se organiza y representa el conocimiento, de ahí que (Nascimiento, D.M.; Marteleto, R.M. citados por Hernández Quintana, 2006) sustente que los procesos de generación, transferencia y uso de la información de las comunidades, son el reflejo de su identificación con objetivos comunes, de la estilización propia de su intercambio de información, y del hecho de que comparten una terminología y ciertos niveles de especialización.

En pos de develar los significados construidos por las comunidades virtuales, el PI debe repasar y analizar teorías provenientes de otras ciencias como la Comunicación que le permitan una mejor comprensión de las relaciones mediáticas ${ }^{10}$.

Barbero (2001) subraya que las Hipermediaciones son "procesos de intercambio, producción y consumo simbólico que se desarrolla en un entorno caracterizado por una gran cantidad de sujetos, medios y lenguajes interconectados tecnológicamente de manera reticular entre sí."

El autor aboga por no segmentar el proceso comunicativo para estudiarlo, sino que lo ve como una imbricación de prácticas y agentes sociales. De ahí su propuesta de acercarse a la comunicación a través de la cultura, mediante el análisis de un conjunto de procesos sociales que tienen lugar en la actualidad.

\footnotetext{
${ }^{9} \mathrm{El}$ Análisis del Discurso investiga por qué y para qué se utiliza la lengua, y tiene como punto de partida al texto. Permite representar estadios de conocimiento y experiencia de los productores de los textos, en forma de modelos funcionales de corte semántico. Sardua, A. (2005). Estudio de la inclusión del Análisis del Discurso en la organización y representación de la información conocimiento para la Bibliotecología y Ciencia de la Información. Trabajo de Diploma en Bibliotecología y Ciencia de la Información. Pp.10.

${ }^{10}$ Formas en las que suceden las interacciones en el medio digital.
}

TENDENCIAS DE LA ORGANIZACIÓN Y REPRESENTACIÓN DEL CONOCIMIENTO EN LA WEB: BLOG, TAXONOMÍAS, FOLKSONOMÍAS, ONTOLOGÍAS, WEB SEMÁNTICA

Desde la aparición desde hace ya más de dos décadas la World Wide WEB, se ha convertido en un instrumento de cotidiano uso para la sociedad. Su evolución no descansa, los intentos de perfeccionarla son continuos en la medida que los usuarios exigen más de ella.

Hoy los usuarios tienen la posibilidad de convertirse en emisores de información a través de herramientas como los blogs, los cuales enfrentan hoy una constante evolución; pero mantienen la misma filosofía para crear, compartir y opinar en la WEB.

Los WEBlogs, blogs o bitácoras, "son aquellos recursos informativos, en formato $W E B$, ya sea en forma textual o de imágenes, en los que una persona o grupo de personas (naturales o juridicas), introducen por orden cronológico noticias, opiniones, sugerencias, articulos, reflexiones o cualquier otro tipo de contenido que consideran de interés, los cuales enlazan frecuentemente a otros recursos WEB y cuya réplica está o no permitida según el propietario del WEBlog” (Ferrada, M. 2005).

A la luz de hoy se pude hablar de la existencia de una cultura blogosférica ${ }^{11}$, cultura asumida por esta comunidad al organizar su información de formas específicas donde no media ningún tipo de regla.

Una de las tendencias que puede repercutir en el futuro de la WEB a mediano plazo, es la visión de lo que se ha dado a llamar la WEB Semántica. Proyecto que pretende mejorar el acceso, recuperación y uso de la información dando solución a los actuales problemas que presenta la WEB.

Para alcanzar el perfeccionamiento de la WEB Semántica en el contexto actual, es clave concebir un diálogo entre todos los implicados.

\footnotetext{
${ }^{11}$ Blogosfera, blogsfera, blogalaxia o blogósfera es el término bajo el cual se agrupa la totalidad de WEBlogs y se deriva de la palabra inglesa blogosphere. Debido a que los blogs o las bitácoras están conectadas por medio de enlaces, comentarios, históricos y referencias han creado y definido su propia cultura. Por lo tanto, la blogosfera como palabra y concepto es inherente a los WEBlogs.
} 
La WEB semántica es una extensión del WEB cuya idea básica es tener los datos definidos y relacionados para que su uso sea más efectivo y sea posible su automatización, integración y reutilización por medio de diferentes aplicaciones, es decir, pretende proporcionar una infraestructura que permita que las páginas WEB, las bases de datos, los programas y aplicaciones, los dispositivos, tanto personales como los empleados en el hogar, puedan consumir y producir datos, sin los problemas causados por los diferentes protocolos de acceso a la información que hacen de la transferencia de contenidos una tarea ardua y difícil. El soporte principal para la organización, almacenamiento y distribución de la información siguen siendo los sistemas taxonómicos, es decir, sistemas de clasificación que respondan a necesidades concretas de las empresas, bibliotecas y centros de información en favor no sólo de los usuarios humanos, sino de las máquinas también (Rodríguez, K; Ronda, R. 2005).

Para conseguirlo sería necesario proporcionar de semántica a la WEB. Los intentos por dotar de semántica a la WEB guardan relación con las Taxonomías, Folksonomías y Ontologías.

Una taxonomía es una estructura predeterminada que se usa para dividir un área temática en otras áreas progresivamente más pequeñas con el propósito de representar no al mundo real, sino a objetos que hablan de ese mundo y por tanto tienen un valor de meta-representación. (Bosch, M. 2006)

La taxonomía sirve también como instrumento de navegación, por lo que su construcción no es una tarea simple; requiere para ello el vínculo entre varias disciplinas para lograr objetivo.

A decir de las Folksonomías (Wright, A. 2004) expone que pueden definirse como una clasificación social que se genera por consenso a través de las aportaciones de los usuarios. Otros criterios son participe de que pueden interpretarse como reflejo de un poder popular.

Las Folksonomías constituyen una forma de interpretar las realidades de los dominios a través de los términos que representan en la WEB, donde lo social tiene un papel preponderante.

En el caso de las ontologías suponen la descripción y representación de un dominio concreto mediante conceptos, atributos, valores, relaciones, funciones, etc., definidas explícitamente (Jesus \& Juan Antonio, 2008).

Las ontologías favorecen la comunicación entre los grupos del dominio, debido a que son generadas de forma consensada dentro del contexto, permitiéndoles a sus miembros la utilización de los términos y la reutilización del conocimiento.

\section{CONSIDERACIONES FINALES}

Las actividades de la organización del conocimiento se han afianzado hoy como una de las más importantes áreas de desarrollo profesional para los PI. El mundo nunca acumuló mayor cantidad de información en medios tan diversificados como con los que contamos hoy. De hay que los PI deben moverse hacia la asimilación de nuevas posturas en su quehacer, generando capacidades de adaptabilidad y flexibilidad en pos de desafiar nuevas problemáticas.

Su inserción en escenarios diversos, le proporcionan la oportunidad de desarrollar actitudes y habilidades para Organizar y Representar el Conocimiento en la WEB, convocándolo a:

a) Desarrollar una Cibercultura que les permita nuevas maneras de innovar y crear no sólo para entender aquellas realidades de las representaciones sociales.

b) Estudiar los recursos construidos en la Red por los dominios para incorporar nuevos métodos de análisis que les permita desarrollar nuevos métodos de representación, valiéndose de métodos heurísticos y hermenéuticos que lo ayuden a interpretar y hacer inferencias.

c) Introducir en el abordaje y proceder de la organización y representación del conocimiento teorías y propuestas provenientes de métodos de 
investigación como el Análisis de Dominio y los Estudios Etnográficos.

d) Incorporar, las nuevas propuestas del etiquetado social que se centra en la amplia gama de posibilidades de representación del conocimiento desde los significados y las riquezas interpretativas de los usuarios, sin la mediación de vocabularios controlados. Lo que permite la comunicabilidad, la contextualización y el tratamiento de la intersubjetividad en los sistemas de representación del conocimiento.

e) Tratar el lenguaje natural para la incorporación de nuevas categorías gramaticales como adjetivos, verbos, adverbios, prefijos en la resignificación de los contenidos.

En este sentido, la implicación del PI en los fenómenos mencionados, a través de su formación y especialización es de suma importancia, como vía de actualización en cuanto a novedad en métodos, teorías y herramientas que apoyan los procesos de Organización y Representación del Conocimiento.

Hasta aquí han sido esbozadas algunas de las habilidades que debe poseer el PI para organizar y representar conocimiento en la WEB, si bien pudieran existir otras que ha de incorporar a su accionar diario para alcanzar uno de sus mayores retos: la construcción de una WEB que se parezca al ser bumano, capaz de interpretar, inferir y asociar.

Artigo submetido em 16/07/2009 e aceito em 03/02/2011.

\section{REFERENCIAS}

BOSCH, M. (2006). La indización asistida para el manejo del conocimiento en organizaciones frente al tratamiento documental en bibliotecas. Extraído el 29 de marzo de 2009 desde http://eprints.rclis.org/ archive/00005870/01/2005_bosch.pdf

CASTELS, M. (1999) La era de la información. Economía, sociedad y cultura. La sociedad red. México D.F. Siglo Veintiuno Editores. 104 p.

CHOO, W. (1999). La organización inteligente: el empleo de la información para dar significado, crear conocimiento y tomar decisiones. México D.F: Oxford México. 346 p.

CODINA, L. (2001). Las propiedades de la información digital. El profesional de la información, v.10, n.12, pp.18-25.

CONTRERAS, J.; MARTÍNEZ-COMECHE, J. Ontologías: ontologías y recuperación de información, 2008.

FERRADA CUBILLOS, M. (2005). WEBlogs o bitácoras: un recurso de colaboración en línea para los Profesionales de la Información. Serie Bibliotecología y Gestión de información No 6.

GARCÍA GUTIERREZ A. L. Tratamiento y análisis de la documentación. En: Vizcaya Alonso, D. (comp). Selección de lecturas: Fundamentos de la organización de la información. La Habana: Universidad de La Habana, 2002.

HJORLAN, B. (s.a). Domain Analysis in Information Science. Extraído el 28 de marzo de 2009 desde http://dlist.sir.arizona.edu/2266/01/ Domain_Analysis_in_LIS.ppt

HJORLAN, B. (2005). Knowledge Organization. Extraído el 25 de marzo de 2009 desde http://dlist.sir.arizona.edu/1050/

JODELET, D. (1988). La representación social: fenómenos, concepto y teoría. Barcelona: Paidós.

LÓPEZ YEPES, J. (2004). Diccionario Enciclopédico de Ciencias de la Documentación, 2 vols. ed. Madrid: Síntesis.

MARTÍN BARBERO, J. (2001). Reconfiguraciones comunicativas de lo público. Departamento de Estudios Socioculturales. Guadalajara. México. Extraído el 12 de abril de 2009 desde www.portalcomunicacion. com/esp/pdf/dest/habermas/0211217526071.pdf

MUELA-MEZA, Z. M. (2004). Una introducción a las metodologías de investigación cualitativa aplicadas a la bibliotecología. LIBER: Revista de Bibliotecologiá, v. 6, n. 2. Extraído el 25 de marzo de 2009 desde http://eprints.rclis.org//archive/00003638/01/zapopan.pdf

NASCIMENTO, D.M.; MARTELETO, R.M. (2004). A informação construida nos meandros dos conceitos da Teoria Social de Pierre Bourdier. DataGramaZero, v.5, n.5.

NONAKA, I; TAKEUCHI,H. (1997). Criação de conbecimento da empresa. Rio de Janeiro: Campus.

RODRÍGUEZ PEROJO, K; RONDA LEÓN, R. (2005). WEB semántica: un nuevo enfoque para la organización y recuperación de información en el WEB. Acimed; v. 13, n.6. Extraído el 7 de abril de 2009 desde http:// bvs.sld.cu/revistas/aci/vol13_6_05/aci030605.htm

WRIGHT, A. (2004) "Folksonomy". Extraído el 7 de abril de 2009 desde http://www.alexwright.org/blog/archives/000900.html 